\title{
Supply and Demand in Prehistory? Economics of Neolithic Mining in NW Europe (NEOMINE)
}

\author{
Stephen Shennan*, Andy Bevan*, Kevan Edinborough*, Tim Kerig', \\ Mike Parker Pearson* and Peter Schauer*
}

\section{Publisher's Note}

The acknowledgement was updated after the print version of this paper had been distributed.

\section{Project Background}

Its overall aim is to address the question of what factors influenced non-agricultural production in prehistory. Explicitly or implicitly this has long been a topic of debate in prehistoric studies, because it relates to the question of whether people in prehistoric societies had 'economic' motivations and what those might have been.

The NEOMINE project is approaching this general issue by analysing the evidence for Neolithic stone quarrying and flint mining and factors potentially affecting consumption of their products in Britain and North West Europe over the period c.5300-2000 BC. This is to address the question: what economic factors, if any, had an influence on their scale and intensity? In particular, did the amount of material the quarries and mines produced vary over time in response to external demand generated by the surrounding population, and, if so, in what ways? It is known from ethnography, for example

\footnotetext{
* UCL Institute of Archaeology, London WC1H OPY, UK

+ University of Leipzig, DE

Corresponding author: Stephen Shennan (s.shennan@ucl.ac.uk)
}

(Pétrequin and Pétrequin 1993), that the factors affecting demand for stone axes in what is now known as Western New Guinea were very complex, but certainly included external demand.

We now know that the quarries and mines of the Neolithic were often major enterprises, producing quantities of artefacts far beyond any imaginable requirement for local use; for example, the Rijckholt mines (Netherlands) are estimated to have produced between 13 and 61 million $\mathrm{kg}$ of flint over a period of 600 years (Felder, Rademakers and de Grooth 1998: 75-77).

Their products were often distributed over hundreds of kilometres and studies over the years have documented the distribution of material from some of the best-known sources (e.g. Clough and Cummins 1979; Pétrequin et al. 2012; Zimmermann 1995). We also have some information on when particular sources were in use (e.g. Rijkholt, above). However, in general, radiocarbon dating of European mining activity is patchy at best and at worst highly skewed towards a few well known sites such as Grime's Graves in Norfolk. Moreover, with the exception of Schyle's (2006) study, no one has systematically addressed the economic factors that might have affected the amount that was produced by different mines at different times. Indeed, after a period of strong interest in the nature of prehistoric production and exchange in the 1970s and 1980s, such economic approaches have largely fallen out of favour, especially among scholars of European prehistory. There has been an 
emphasis on cultural differences as an explanation for variation in practices.

The NEOMINE project is focussed on Britain and NW Europe because this region contains a large number of important flint mines and stone quarries, and a great deal of fieldwork and scientific work on identifying raw material sources has taken place here over recent decades. However, with few exceptions, especially the work of Pétrequin and colleagues on the axes of jadeitite and related material from the Alps of southern France and northern Italy (Pétrequin et al. 2012; Pétrequin, Gauthier and Pétrequin 2017), the results have never been gathered together to ask large-scale questions such as those to be addressed here.

\section{Hypotheses Being Tested}

The overall hypothesis is that the exploitation of mines and quarries in Britain and NW Europe depended on the scale of demand for the products. A variety of factors could potentially have an impact on demand at a given source. They include the size of regional populations, the intensity of forest clearance, the scale of regional/inter-regional social inequality and competition, especially for sources specialising in materials with significant non-utilitarian uses, competition from other stone sources and competition from copper (see e.g. Klassen, Cassen and Pétrequin 2012; Pétrequin and Jeunesse 1995: 111-112). Evaluating the importance of these different factors involves obtaining a reliable measure of the periods of use of individual mines and quarries and reliable independent evidence of the factors themselves.

\section{Methods}

Obtaining a measure of the periods of use of individual mines and quarries requires collating and evaluating all existing radiocarbon dates associated with quarrying and flint-mining activity and collecting a targeted series of new dates where existing dates are not sufficient. It is also necessary to create a database of find locations and the source composition of lithic assemblages at dated consumption sites to reconstruct quarry and mine exchange networks.

Obtaining similar reliable indicators of the factors listed above that might have affected demand, and therefore potentially production, at a particular source, and testing their impact involves a number of different lines of evidence. First, a measure of regional population fluctuations during the Neolithic for the study areas is required so that inferred periods of use of the sources can be correlated with changing population patterns for the surrounding area, to see if mine production responded to changes in the regional population size. This has been done by using summed radiocarbon probabilities as a demographic proxy, on the assumption that the number of radiocarbondated sites of a given date reflects the size of the population at that time (see Shennan et al. 2013; Timpson et al. 2014) for discussion of this assumption). Some sites, including mines, have more dates than others because of differences in excavator research priorities and budgets. To reduce this effect, dates within 100 years of one another at any given site are combined; this is the 100 year 'bin' size shown in Fig. 1. To control even more strongly for this effect, we repeated the comparison between mine dates and hinterland populations with each mine represented by one date only (Fig. 2). Because the dates are geo-referenced, population fluctuations within hinterlands at different distances from mines can be characterised.

\section{Results So Far}

The project has produced a geo-referenced database of 361 mines, quarries and other sources across Europe (https://www.ucl. ac.uk/neomine/maps), with more than 1100 radiocarbon dates coming directly from those mines (often sampled from the antler picks used by the quarry workers). We are currently processing new samples from the Great Langdale 'axe quarries' in the north of England, using material provided by Richard Bradley from his earlier fieldwork (Bradley and Edmonds 1993), and archived samples 


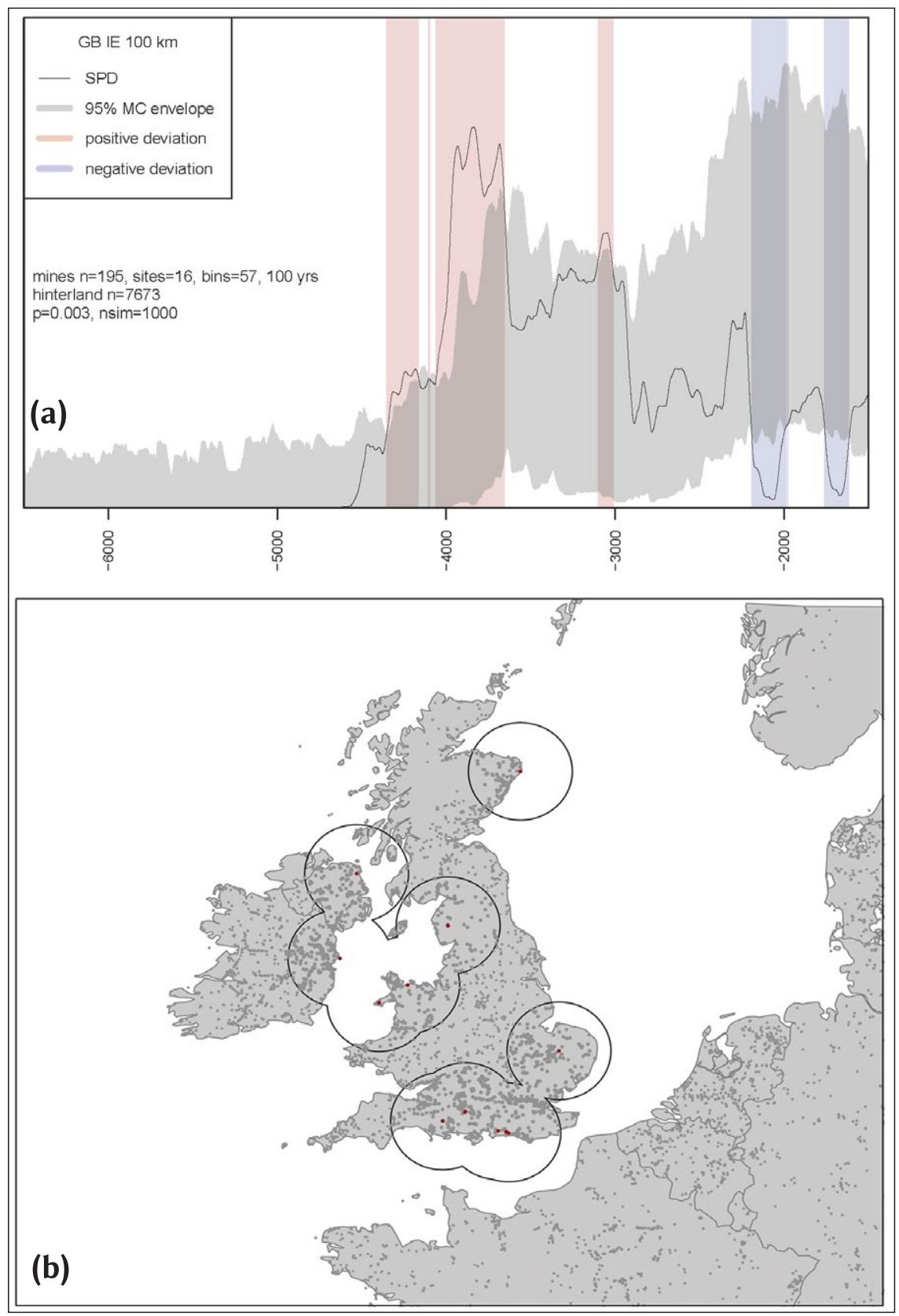

Figure 1: (a) The solid line shows the summed probability distribution (SPD) of the dates from all mines and quarries in Britain and Ireland, with dates grouped into 100 year bins. The grey area shows the $95 \%$ confidence interval derived from generating 1000 samples of dates from sites in the $100 \mathrm{~km}$ radius hinterlands of all the mines/quarries combined. Periods where the mine SPD is higher than the hinterland SPD are shown in pink, periods were it is lower in blue. The overall significance of the departures $=0.003$. The horizontal axis is in years BC. The vertical axis is a probability axis on which only relative values matter so no scale is given. (b) The map shows the locations of the mines and quarries in the analysis and their $100 \mathrm{~km}$ radius hinterlands, including areas of overlap. Dates from sites in areas of overlap are only counted once. 


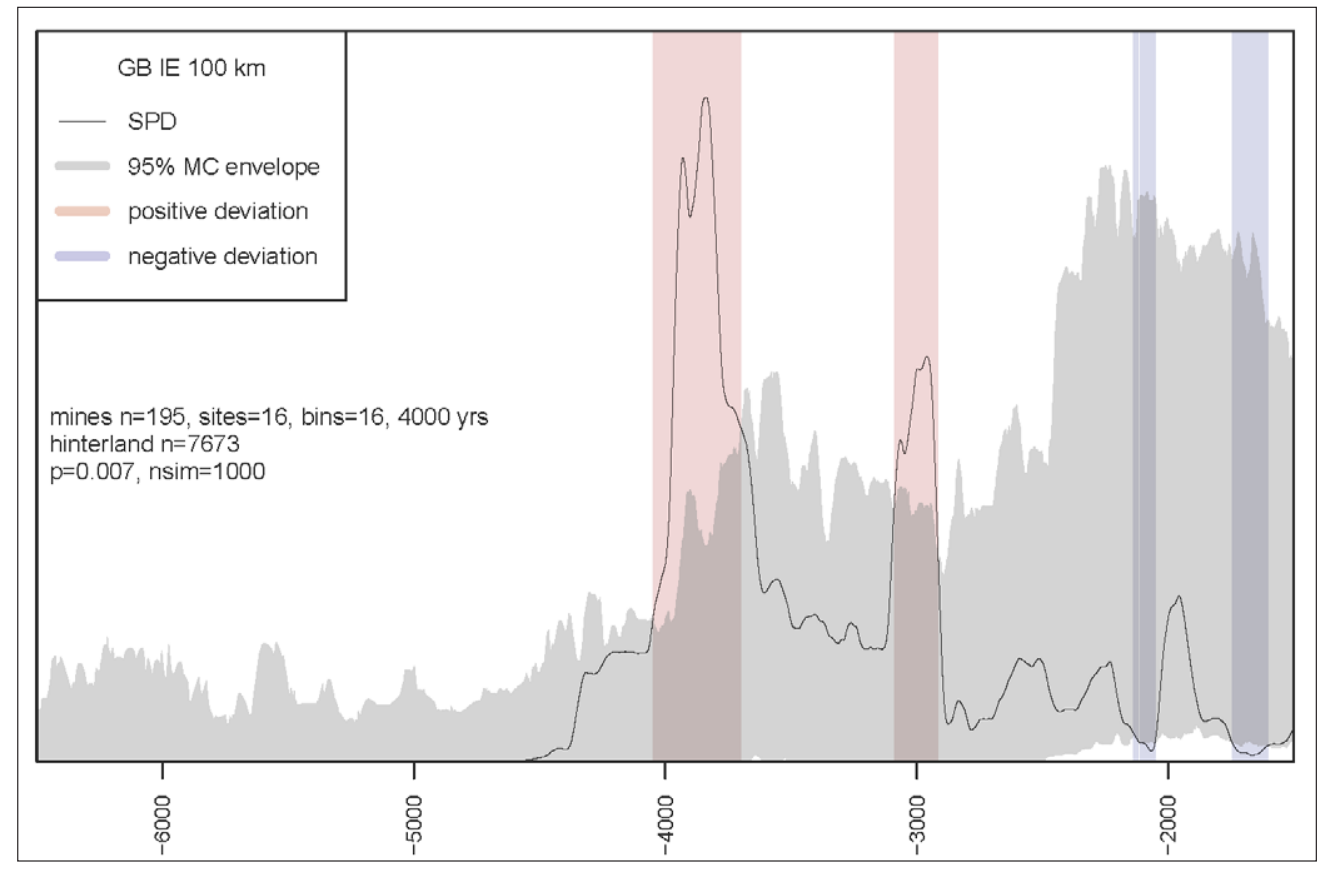

Figure 2: As figure 1 but with only one date per mine or quarry. This is achieved by grouping the dates into 4000 year bins. The overall significance of the departures $=0.007$.

from the South Downs flint mines in the UK. We are also processing samples from ongoing mining excavations in the Marne region of North Eastern France, directed by Rémi Martineau (CNRS, University of Bourgogne). The Scottish Universities Environmental Research Council (SUERC) laboratories are measuring NEOMINE samples, following the latest radiocarbon protocols (Dunbar et al. 2016). For NW Europe as a whole (including France, Germany, the Low Countries, southern Scandinavia, Britain and Ireland) we have collated over 26,000 geo-referenced radiocarbon dates for the period 5500-2000 cal. BC as the basis for constructing the population proxies for the individual mine hinterlands.

We have tested the chronological distribution of our dates for mines and quarries against the radiocarbon population proxy. If the exploitation of mines and quarries depended simply on the scale of demand generated by the population in the surrounding region, then their inferred periods of use would correlate with changing population patterns in the hinterlands around each site: in particular, they would be more likely to be in use when regional populations were high and less so when they were low. This can be tested by comparing the distribution of mine dates with the hinterland dates in a bootstrap analysis. The process involves repeatedly taking random samples of calibrated dates from the hinterland, with the size of the sample corresponding to the number of mine dates, to create a mean confidence envelope. This is the distribution of mine dates through time that would be expected if the size of the regional population was the only factor that influenced it. The result can then be compared with the distribution of real mine and quarry dates. If the pattern for the mines and quarries is significantly different, then we can conclude that activity at the mine or quarry was influenced by factors other than the size of the regional population.

The results for Britain and Ireland are shown in Fig. 1. In this example, the calibrated 
distributions of all the dates from all mines and quarries within this region are aggregated into a single summed probability distribution (SPD), and similarly all the dates from all mine/quarry hinterlands are combined into one large, non-overlapping sample. When this has been done the random samples of hinterland dates can be generated for testing against the mine date distribution. Combining the mines and hinterlands in this way allows us to make statements about the general relationship between mines and hinterlands in Britain and Ireland. The hinterland distance of $100 \mathrm{~km}$ was chosen after testing the relationship between hinterlands of varying sizes and finding that this provided the best balance between sample size and the scale of the mine and quarry product distributions. Of course, some products from many sites travelled much further than $100 \mathrm{~km}$, and in later work we will repeat this test using a hinterland shaped by the actual distribution of products from known sources.

The results show that there is a significant difference between the mine and quarry site SPD and the hinterland mean confidence envelope. In particular, we can see that mine activity accelerated rapidly after beginning around 4500 cal. BC, in advance of the Neolithic population increase in Britain and Ireland, leading the population curve by around 200 years (though our method will tend to exaggerate the effect of the early end of the individual date probability distributions for both the mines and the population). Since the main products of the mines and quarries were axes it seems likely that this corresponds to a period of forest clearance by the immigrant groups who introduced farming to Britain and Ireland at this time (Olalde et al. 2017). Mining activity then declined, before rising again around $3000 \mathrm{cal}$. BC. The hinterland population decreased sharply after this, and when it recovered from $2500 \mathrm{cal}$. BC onwards, flint and stone mining did not return, probably because the first copper metallurgy was introduced at this time. The pattern was the same whether we used 100 year 'bins' for the mine dates (Fig. 1) or reduced the dates even more, to only one per mine (Fig. 2).

\section{Immediate Next Steps}

Next we will compare the distribution of mine dates with changes in regional intensity of forest clearance, using pollen data, to test the suggestion made above that mine exploitation leads the population curve because it reflects initial forest clearance by farmers. We will also test for correlation between the decline of large-scale mine and quarry production and the appearance of copper items within each source's region of distribution.

\section{Acknowledgements}

We are extremely grateful to the Leverhulme Trust for Research Project Grant RPG-2015-199 that is making this project possible. This project began in December 2015 and will run until February 2019. The radiocarbon results shown in the figures draw primarily on the EUROEVOL radiocarbon dataset, expanded via further attention to recent journal and book publications, Chapple, R (2015) Irish Radiocarbon and Dendrochronological Dates (https://sites.google.com/site/chapplearchaeology/irish-radiocarbon-dendrochronological-dates), the ADS grey literature archive, Historic England's published date lists and consultation of the Canmore and Museum of Wales radiocarbon databases.

\section{Competing Interests}

The authors have no competing interests to declare.

\section{Authors' Contribution}

The principal investigators are Stephen Shennan, Andy Bevan and Mike Parker Pearson of the UCL Institute of Archaeology and Tim Kerig from Leipzig University, Germany. The project has two post-doctoral researchers, Kevan Edinborough and Peter Schauer.

\section{References \\ Bradley, R and Edmonds, M 1993 Interpreting the Axe Trade. Cambridge: Cambridge UP.}


Clough, T H and Cummins, W A 1979 Stone axe studies: archaeological, petrological, experimental and ethnographic. London: Council for British Archaeology.

Dunbar, E, Cook, G T, Naysmith, P, Tripney, B G and Xu, S 2016 AMS 14C dating at the Scottish Universities Environmental Research Centre (SUERC) Radiocarbon Dating Laboratory. Radiocarbon, 58(1): 9-23. DOI: https://doi.org/10.1017/ RDC.2015.2

Felder, P J, Rademakers, P and de Grooth, M (Eds.) 1998 Excavations of Prehistoric Flint Mines at Rijckholt-St. Geertruid (Limburg, The Netherlands). Archäologische Berichte, 12. Habelt: Bonn.

Klassen, L, Cassen, $\mathbf{S}$ and Pétrequin, $\mathbf{P}$ 2012 Alpine axes and early metallurgy. In: Pétrequin, P, Cassen, S, Errera, M, Klassen, L and Sheridan, A (Eds.) JADE. Grandes haches alpines du Néolithique européen. Ve et IVe millénaires av. J.-C. Besançon: Presses Universitaires de Franche-Comté, pp. 1280-1309.

Olalde, I, Brace, S, Allentoft, M E, Armit, I, Kristiansen, K, Rohland, N, Mallick, S, Booth, T, Szécsényi-Nagy, A, Mittnik, A and Altena, E 2017 The Beaker phenomenon and the genomic transformation of northwest Europe. bioRxiv. DOI: https:// doi.org/10.1101/135962

Pétrequin, P, Cassen, S, Errera, M, Klassen, L and Sheridan, A (Eds.) 2012 JADE. Grandes haches alpines du Néolithique européen. Ve et IVe millénaires av. J.-C. Besançon: Presses Universitaires de Franche-Comté.

Pétrequin P, Gauthier $\mathbf{E}$ and Pétrequin $\mathbf{A}$ 2017 JADE. Objets-signes et interpreta- tions sociales des jades alpins dans l'Europe néolithique. Besançon: Presses Universitaires de Franche-Comté.

Pétrequin, P and Jeunesse, C 1995 La hache de pierre. Carrières vosgiennes et échanges de lames polies pendant le Néolithique - 54002100 avant J.-C. Paris: Errance.

Pétrequin, P and Pétrequin, A 1993 Ecologie d'un outil: la hache de pierre en Irian Jaya. Paris: CNRS.

Schyle, D 2006 Die spätneolithische Beilproduktion auf dem Lousberg in Aachen. Eine Hochrechnung von Angebot und Nachfrage und Rückschlüsse auf die spätneolithische Bevölkerungsdichte. Archäologische Informationen, 29(1\&2): 35-50. DOI: http:// dx.doi.org/10.11588/ai.2006.1\&2.11094

Shennan, S, Downey, S S, Timpson, A, Edinborough, K, Colledge, S, Kerig, T, Manning, K and Thomas, M G 2013 Regional population collapse followed initial agriculture booms in mid-Holocene Europe. Nature Communications, 4: 2486. DOI: https://doi.org/10.1038/ ncomms3486

Timpson, A, Colledge, S, Crema, E, Edinborough, K, Kerig, T, Manning, K, Thomas, M G and Shennan, S 2014 Reconstructing regional demographies of the European Neolithic using radiocarbon dates: a new case-study using an improved method. Journal of Archaeological Science, 52:549-557.DOI:https://doi.org/10.1016/ j.jas.2014.08.011

Zimmermann, A 1995 Austauschsysteme von Silexartefakten in der Bandkeramik Mitteleuropas. Bonn: Habelt.

\footnotetext{
How to cite this article: Shennan, S, Bevan, A, Edinborough, K, Kerig, T, Parker Pearson, M and Schauer, P 2017 Supply and Demand in Prehistory? Economics of Neolithic Mining in NW Europe (NEOMINE). Archaeology International, No. 20: pp. 74-79, DOl: https://doi.org/10.5334/ai-358

Published: 14 December 2017

Copyright: (c) 2017 The Author(s). This is an open-access article distributed under the terms of the Creative Commons Attribution 4.0 International License (CC-BY 4.0), which permits unrestricted use, distribution, and reproduction in any medium, provided the original author and source are credited. See http://creativecommons.org/licenses/by/4.0/.
} 